\title{
ANALISA KEKERASAN DAN STRUKTUR MIKRO PADA BAJA AISI 1018 AKIBAT PROSES PACK CARBURIZING DENGAN VARIASI KONSENTRASI SERBUK CANGKANG KEONG EMAS
}

\author{
Achmad Zainuri, Paryanto Dwi Setyawan, Prayuda atmam \\ Jurusan Teknik Mesin Fakultas Teknik Universitas Mataram \\ Email: achmadzainuri70@yahoo.co.id
}

\begin{abstract}
This research to investigate the effect of Pomacea Canalikulata Lamarck powder addition in the process of carburization box to physical (microstructure) and mechanical properties (hardness test) of AISI 1018 after heat treatment. In this research used a material of low carbon steel cylinder (AISI 1018). The process of making the specimen is done with to cut into several pieces, cutting done to ease in placing the specimen in the carburizing box, then wood charcoal powder and shell powder were weighed in accordance with the desired composition by mixing powder of $5 \mathrm{wt} \%, 10 \mathrm{wt} \%$, and $15 \mathrm{wt} \%$. The specimen was done heat treatment at a temperature of $950^{\circ} \mathrm{C}$ with the holding time at 2,4 and 6 hours. Then, the specimen was done the Vickers hardness test, microstructure and composition test. From this research it can be concluded that the highest hardness value was obtained at $15 \mathrm{wt} \%$ addition of shell powder it was $262.26 \mathrm{~kg} / \mathrm{mm}^{2}$ and the initial material hardness value was 144.08 $\mathrm{kg} / \mathrm{mm}^{2}$. From microstructure observation and composition test show that it subjected surface hardening because carbon diffusion into specimen.
\end{abstract}

Keywords: Pomacea Canalikulata Lamarck, pack carburizing, hardness test, composition test, microstructure

\begin{abstract}
ABSTRAK
Tujuan dari penelitian ini adalah untuk mengetahui pengaruh penambahan serbuk cangkang keong emas pada proses pack carburizing terhadap sifat fisis (struktur mikro) dan mekanis (uji kekerasan) baja karbon rendah setelah mengalami perlakuan. Bahan yang digunakan dalam penelitian ini adalah baja karbon rendah yang berbentuk selinder. Proses pembuatan spesimen dilakukan dengan pemotongan menjadi beberapa bagian, pemotongan dilakukan untuk memudahkan di dalam meletakan spesimen di dalam kotak karburisasi,kemudian serbuk arang kayu dan serbuk cangkang ditimbang sesuai dengan komposisi yang diinginkan dengan pencampuran serbuk cangkang 5, 10 dan 15 (\% berat). Spesimen dilakukan perlakuan panas pada temperatur $950^{\circ} \mathrm{C}$ dengan penahanan waktu selama 2, 4 dan 6 jam. Kemudian dilakukan Uji kekerasan Vickers, pengujian foto struktur mikro dan uji komposisi. Dari penelitian ini dapat disimpulkan bahwa nilai kekerasan tertinggi rata-rata pada penambahan $15 \%$ serbuk cangkang di peroleh sebesar 262,26 kg/mm² dan kekerasan material awal diperoleh sebesar 144,08 $\mathrm{kg} / \mathrm{mm}^{2}$. Dari hasil pengamatan struktur mikro dan uji komposisi diketahui bahwa terjadi pengerasan permukaan karena difusi karbon kedalam baja karbon randah.
\end{abstract}

Kata Kunci : Cangkang keong emas, pack carburizing, uji kekerasan, uji komposisi, struktur mikro 


\section{PENDAHULUAN}

Hasil alam Indonesia sangat melimpah, termasuk beberapa jenis hewan yang terdapat di dalamnya. Salah satunya adalah Keong emas (Pomacea Canalikulata Lamarck) yang merupakan salah satu hewan jenis moluska. Hewan jenis ini paling sering dijumpai di daerah persawahan dan merupakan musuh petani karena dapat merusak tanaman padi. Untuk melindungi tanamannya, para petani berusaha untuk membasmi keong emas sehingga tanaman petani dapat terhindar dari kerusakan. Ternyata keong emas yang semula hanya merugikan para petani kini dapat dimanfaatkan karena cangkang keong emas mengandung kalsium karbonat $\left(\mathrm{CaCO}_{3}\right)$ yang dapat dijadikan sebagai energizer alternatif di dalam proses karburisasi padat selain barium karbonat $\left(\mathrm{BaCO}_{3}\right)$.

Pada dasarnya bahan-bahan yang digunakan dalam karbonisasi yaitu, arang kayu, arang batok kelapa, dan arang kulit. Untuk mempercepat proses karbonasi maka di tambahkan barium karbonat $\left(\mathrm{CaCO}_{3}\right)$, natrium karbonat $\left(\mathrm{NaCO}_{3}\right)$ atau kalsium karbonat $\left(\mathrm{CaCO}_{3}\right)$. Ketiga bahan tambahan tersebut termasuk jenis bahan-bahan pembangkit tenaga dalam proses karburisasi. Karburisasi dilakukan dengan cara memanaskan bahan sampai $900-950^{\circ} \mathrm{C}$ dalam lingkungan yang menyerahkan karbon, lalu dibiarkan beberapa waktu lamanya pada suhu tersebut dan kemudian didinginkan. (Amanto, H. \& Daryanto, 1999).

Setiyawan (2003), mengadakan penelitian mengenai pengaruh proses carburizing terhadap sifat fisis dan mekanis sudu blower dinamo ampere pada mobil diesel didapatkan kesimpulan bahwa lama waktu penahanan (holding time) pada material ini mempengaruhi sifat mekanis material yaitu terhadap nilai kekerasan. Dimana material dasar tanpa perlakuan memiliki kekerasan rata-rata sebesar $664,1 \mathrm{~kg} / \mathrm{mm}^{2}$, material hasil quenching $850{ }^{\circ} \mathrm{C}$ dengan holding time 1 jam sebesar 723,64 kg/mm² dan material hasil quenching $850{ }^{\circ} \mathrm{C}$ dengan holding time 2 jam sebesar $730,5 \mathrm{~kg} / \mathrm{mm}^{2}$.

Fatai dkk (2010) menyelidiki proses pack carburizing pada mild steel dengan temperatur karburisasi $850^{\circ} \mathrm{C}, 900^{\circ} \mathrm{C}$ dan $950^{\circ} \mathrm{C}$, kemudian ditahan selama 15 menit dan 30 menit, lalu proses quenching dengan minyak dan tempering pada $550^{\circ} \mathrm{C}$. Hasil pengujian menunjukkan bahwa ketangguhan impact pada mild steel semakin berkurang dengan naiknya temperatur karburisasi. Sedangkan kekakuan dari mild steel semakin meningkat akibat proses karburisasi, tetapi semakin turun dengan kenaikan temperatur karburisasi. Untuk kekerasan permukaan pada mild steel semakin berkurang dengan naiknya temperatur.

Tujuan dari penelitian ini adalah untuk mengetahui pengaruh penambahan serbuk cangkang keong emas pada proses pack carburizing terhadap sifat fisis (struktur mikro) dan mekanis (uji kekerasan) baja karbon rendah setelah mengalami perlakuan.

\section{Pack Carburizing}

Proses carburizing merupakan proses penambahan unsur karbon $(\mathrm{C}) \mathrm{ke}$ dalam logam khususnya pada bagian permukaan bahan dimana unsur karbon ini didapat dari bahan-bahan yang mengandung karbon sehingga kekerasan logam dapat meningkat. Pengerasan permukaan pada logam dapat dilakukan dengan menambahkan unsur-unsur tertentu ke logam dasar tersebut seperti karbon, kalsium karbonat, nitrogen, dan yang lainnya. Untuk mempercepat proses maka ditambahkan barium karbonat $\left(\mathrm{BaCO}_{3}\right)$, 
kalsium karbonat $\left(\mathrm{CaCO}_{3}\right)$ atau natrium karbonat $\left(\mathrm{NaCO}_{3}\right)$ sebagai energizer yang bersama-sama material dimasukkan ke dalam kotak kedap udara untuk dipanaskan pada dapur pemanas pada temperatur carburing (Suherman, 1987).

Pada pengarbonan padat dipakai arang yang dicampur dengan 10\%-40\% $\mathrm{NaCO}_{3}, \mathrm{BaCO}_{3}$, baja dimasukkan ke dalam campuran ini, ditempatkan dalam suatu kotak dan ditutup rapat kemudian dipanaskan pada temperatur $850^{\circ} \mathrm{C}-$ $950^{\circ} \mathrm{C}$ (Surdia, 2000). Setelah dilakukan holding time (waktu penahanan), proses dilanjutkan dengan pengerasan dengan quenching untuk mencapai kekerasan yang tinggi, dan tempering untuk menurunkan kegetasan dan tegangan sisa yang berlebihan.

\section{Keong Emas}

Keong Emas ((Pomacea canaliculata Lamarck) atau dikenal GAS (Golden Apple Snail). Keong Emas merupakan salah satu jenis moluska. Keong ini berasal dari rawa-rawa di Amerika Selatan seperti Brazil, Suriname dan guatemala. Pertama kali, Keong Emas ini didatangkan dari Taiwan sekitar tahun 1980-an. Tahun 1981, hewan ini diintroduksi ke Yogyakarta sebagai fauna akuarium. Sekitar tahun 19851987, hewan ini menyebar dengan sangat cepat dan populer di Indonesia (Jekti, 1990).

Keong Emas muda berukuran 2-5 mm telah memakan alga dan bagian tanaman yang lunak. Pertumbuhan awal berlangsung selama 15-25 hari. Pada umur 26-59 hari, Keong Emas sangat rakus mengkonsumsi makanan, sedangkan setelah berumur 60 hari, Keong Emas siap untuk berkembang biak. Keong Emas memerlukan sekitar 3-4 jam pada saat mengadakan perkawinan di daerah yang senantiasa mendapatkan air sepanjang tahun. Profil Keong Emas dapat dilihat pada Gambar 1 di bawah ini.

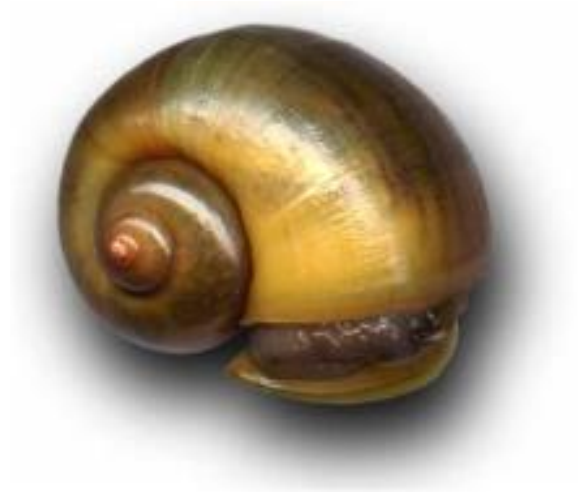

Gambar 1: Keong Emas

\section{Pengujian Kekerasan}

Proses pengujian kekerasan dengan metoda Vickers mula-mula permukaan logam yang akan diuji ditekan dengan indentor berbentuk piramida intan yang dasarnya berbentuk bujur sangkar. Besar sudut antara permukaan-permukaan piramida yang berhadapan adalah sebesar $136^{\circ}$.

$$
\text { Angka kekerasan Vickers }
$$
(VHN) merupakan angka kekuatan benda uji terhadap pembebanan pada tiap luas penampang bidang yang menerima pembebanan (Koswara, 1999). VHN dapat diperoleh dengan persamaan berikut:

$$
V H N=\frac{\{2 \cdot P \cdot \sin (a / 2)\}}{d^{2}}=1,854 \cdot \frac{P}{d^{2}}
$$

Dimana, $\mathrm{P}=$ Beban yang digunakan $(\mathrm{kg}) ; \alpha=$ Sudut puncak indentor $=136^{\circ}$ dan $\mathrm{d}=$ Panjang diagonal rata-rata (mm).

Pengujian Vickers memiliki banyak keuntungan. Pengujian Vickers dapat dilakukan tidak hanya pada benda yang lunak akan tetapi juga dapat dilakukan pada bahan yang keras. Bekas penekanan yang kecil pada pengujian Vickers mengakibatkan kerusakan bahan percobaan relatif sedikit. Pada benda kerja yang tipis atau lapisan 
permukaan yang tipis dapat diukur dengan gaya yang relatif kecil.

\section{Pengujian Struktur Mikro}

Struktur bahan dalam orde kecil sering disebut struktur mikro. Struktur ini hanya dapat dilihat dengan menggunakan alat pengamat struktur mikro diantaranya : mikroskop electron, mikroskop field ion, mikroskop field emission, dan mikroskop sinar - X.

Persiapan yang harus dilakukan sebelum mengamati struktur mikro adalah pemotongan spesimen, pengampelasan dan pemolesan dilanjutkan pengetsaan. Setelah permukaan spesimen rata betul kemudian dilanjutkan dengan proses pengampelasan dengan nomor kekasaran yang berurutan dari yang paling kasar (nomor kecil) sampai yang halus (nomor besar). Arah pengampelasan tiap tahap harus diubah, pengampelasan yang lama dan penuh kecermatan akan menghasilkan permukaan yang halus dan rata. Pemolesan dilakukan dengan autosol yaitu metal polish, bertujuan agar didapat permukaan yang rata dan halus tanpa goresan sehingga terlihat mengkilap seperti kaca. Kemudian mencelupkan spesimen dalam larutan etsa dengan posisi permukaan yang dietsa menghadap keatas. Selama pencelupan akan terjadi reaksi terhadap permukaan specimen sehingga larutan yang menyentuh spesimen harus segar/baru, oleh karena itu perlu digerak-gerakkan. Kemudian spesimen dicuci, dikeringkan dan dilihat atau difoto dengan mikroskop logam. Pemeriksaan struktur mikro memberikan informasi tentang bentuk struktur, ukuran dan banyaknya bagian struktur yang berbeda.

\section{METODOLOGI PENELITIAN}

\section{Alat dan Bahan}

Adapun alat-alat yang akan dipersiapkan sebelum melakukan penelitian ini adalah sebagai berikut Kotak karburisasi, tungku pemanas, Mesin polish, Mikroskop optik, Mesin uji kekerasan, Jangka sorong, Kamera, Tang penjepit, dan Amplas

Sedangkan bahan yang akan digunakan adalah baja AISI 1018, arang kayu jati, serbuk cangkang Keong Emas, kertas gosok (dengan ukuran 80, 100, 400, 600, 800, dan 1000), dan Autosol

\section{Persiapan Spesimen}

Spesimen yang dipersiapkan sebanyak 33 buah, yang terdiri dari 3 spesimen awal tanpa karburasi, 27 spesimen dikarburisasi pada suhu $950^{\circ} \mathrm{C}$ selama 2, 4 dan 6 jam dengan dengan penambahan serbuk cangkang Keong Emas sebanyak 5\%, 10\% dan 15\% dengan media pendingin air, dan 3 spesimen dikarburisasi pada suhu $950^{\circ} \mathrm{C}$ selama 4 jam dengan penambahan serbuk cangkang keong emas sebanyak $10 \%$ dengan media pendingin larutan garam.

Kotak terbuat dari baja karbon rendah dengan ketebalan $5 \mathrm{~mm}$ dengan ukuran panjang $100 \mathrm{~mm}$, lebar $100 \mathrm{~mm}$ dan tinggi $100 \mathrm{~mm}$, benda-benda uji tersebut dimasukkan kedalam kotak karburisasi disusun seperti gambar dibawah ini dengan jarak tiap-tiap spesimen.

Dimensi spesimen dapat dilihat pada Gambar 2 berikut ini:

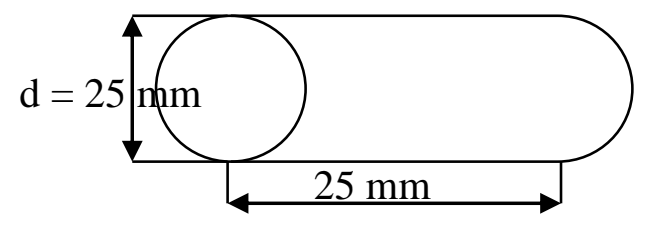

Gambar 2: Dimensi spesimen 


\section{Persiapan Media Pack Carburizing}

Media pack carburizing yang digunakan dalam penelitian ini adalah medium padat, dengan komposisi yang sudah ditentukan dengan perbandingan $95 \%, 90 \%, 85 \%$ arang kayu jati dan 5 $\%, 10 \%, 15 \%$ serbuk keong emas yang ditumbuk sampai berukuran kira-kira 2 sampai $4 \mathrm{~mm}$ kemudian melakukan proses pengayakan sampai dengan ukuran 100 mesh dan ditimbang sesuai dengan komposisi diatas dan dicampur sampai rata.

\section{Proses Pack Carburizing}

Adapun tahapan proses pack carburizing adalah sebagai berikut:

1. Spesimen yang telah dipotong sebanyak 33 buah dan media arang kayu jati yang sudah dicampur dengan bahan energizer dimasukkan ke dalam kotak carburizing sampai berada di tengah-tengah kotak kemudian ditutup lagi lalu dimasukkan ke dalam tungku pemanas.

2. Kotak karburasi ditandai agar tidak tertukar pada waktu pemanasan.

3. Kemudian kotak tersebut dimasukkan ke dalam tungku dan pemanasan diatur dengan perlakuan pemanasan pada temperatur $950^{\circ} \mathrm{C}$, lama pemanasan 2, 4, dan 6 jam.

4. Setelah perlakuan tersebut di atas dilakukan maka kotak dikeluarkan dari dapur pemanas, kemudian kotak di buka dan spesimen dikeluarkan lalu dicelupkan ke dalam air.

5. Spesimen dibersihkan.

Spesimen yang telah melalui proses pack carburizing, selanjutnya dilakukan pengujian. Spesimen yang akan di uji di bersihkan dan diberi tanda sesuai dengan lama pemanasan dan jumlah berat serbuknya, kemudian dilakukan polishing.

\section{HASIL DAN PEMBAHASAN}

\section{Hasil Uji Kekerasan}

Pengujian kekerasan permukaan yang dipakai adalah metode Vickers dengan beban (P) sebesar $60 \mathrm{Kg}$. Pengujian ini dilakukan di Laboratorium Metalurgi Jurusan Teknik Mesin Fakultas Teknik Universitas Mataram. Data hasil uji kekerasan permukaan setelah proses pack carburizing dapat dilihat pada Tabel 1 berikut ini.

Tabel 1: Data hasil uji kekerasan permukaan proses pack carburizing.

\begin{tabular}{|c|c|c|c|}
\hline \multirow{3}{*}{$\begin{array}{l}\text { Waktu } \\
\text { Penahanan } \\
\text { (Jam) }\end{array}$} & \multirow{2}{*}{\multicolumn{3}{|c|}{$\begin{array}{c}\text { Kekerasan Vickers }\left(\mathrm{Kg} / \mathrm{mm}^{2}\right) \\
\text { Variasi konsentrasi } \\
\text { serbuk cangkang (\% Berat) }\end{array}$}} \\
\hline & & & \\
\hline & 5 & 10 & 15 \\
\hline \multirow{3}{*}{2} & 156.82 & 222.1 & 193.84 \\
\hline & 176.03 & 172.54 & 204.43 \\
\hline & 209.30 & 175.69 & 258.27 \\
\hline Rata - rata & 180.71 & 190.77 & 218.84 \\
\hline \multirow{3}{*}{4} & 233.94 & 250.96 & 227.02 \\
\hline & 204.34 & 233.78 & 222.61 \\
\hline & 183.36 & 206.5 & 294.93 \\
\hline Rata - rata & 207.21 & 230.41 & 248.18 \\
\hline \multirow{3}{*}{6} & 241.22 & 250.75 & 290.80 \\
\hline & 234.08 & 252.00 & 246.33 \\
\hline & 229.84 & 260.26 & 249.67 \\
\hline Rata - rata & 235.04 & 254.33 & 262.26 \\
\hline
\end{tabular}

Dari Tabel 1 di atas menunjukkan bahwa setiap penambahan serbuk cangkang Keong Emas terjadi peningkatan nilai kekerasan secara signifikan dimana nilai tertinggi kekerasan rata-rata sebesar 262.26 $\mathrm{kg} / \mathrm{mm}^{2}$ dengan kandungan komposisi serbuk cangkang Keong Emas 15\% ditambah $85 \%$ serbuk arang kayu dengan lama waktu penahan 6 jam pada temperatur pemanasan $950^{\circ} \mathrm{C}$.

Adapun pengaruh konsentrasi serbuk cangkang Keong Emas dan waktu penahan terhadap nilai kekerasan dapat dilihat pada Gambar 3 dan 4 di bawah ini. 


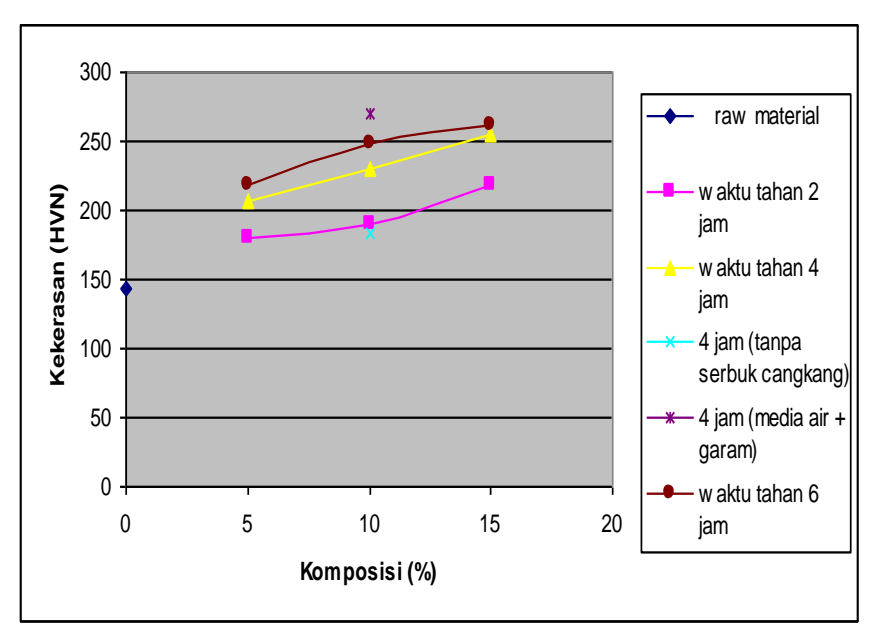

Gambar 3: Grafik hubungan waktu penahanan dan konsentrasi serbuk cangkang terhadap nilai kekerasan.

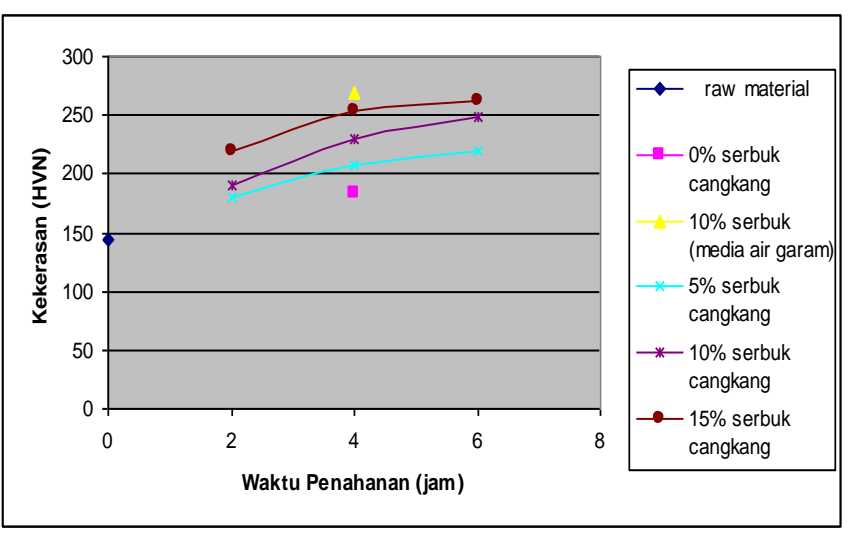

Gambar 4: Grafik hubungan waktu penahanan dan konsentrasi serbuk cangkang terhadap nilai kekerasan.

Dari Gambar 3 dan Gambar 4 di atas menunjukkan bahwa pada spesimen material awal memiliki nilai kekerasan yang sangat rendah ini dikarenakan tidak adanya penambahan karbon pada material. Spesimen dengan waktu pemanasan 2 jam pada suhu $950^{\circ} \mathrm{C}$ memiliki nilai kekerasan lebih keras dibandingkan dengan matarial awal ini dikarenakan adanya karbon aktif dan didukung oleh penambahan serbuk cangkang keong emas sebagai energizer sehingga karbon lebih cepat berdifusi kedalam material. Sedangkan komposisi $15 \%$ serbuk cangkang keong emas mempunyai nilai kekerasan yang paling tinggi setelah mengalami proses pack carburizing pada temperatur $950^{\circ} \mathrm{C}$. Dalam proses ini jika serbuk cangkang keong emas semakin banyak maka karbon yang berdifusi ke baja akan semakin cepat dan membuat nilai kekerasan permukaan dari baja akan semakin besar, sehingga karbon akan lebih mudah berdifusi di antara celahcelah atom $\mathrm{Fe}$. Pada proses carburizing dengan penambahan $10 \%$ serbuk cangkang dengan menggunakan media pendingin larutan air garam diperoleh harga kekerasan tertinggi sebesar $269.38 \mathrm{~kg} / \mathrm{mm}^{2}$ dengan waktu penahanan 4 jam disusul dengan penambahan $15 \%$ serbuk cangkang dengan menggunakan media pendingin air tawar sebesar $262.26 \mathrm{~kg} / \mathrm{mm}^{2}$ dengan waktu penahanan 6 jam dan penambahan $10 \%$ serbuk cangkang dengan media pendingin air tawar $254.33 \mathrm{~kg} / \mathrm{mm}^{2}$, dan penambahan $5 \%$ serbuk cangkang dengan media pendingin air tawar $262.26 \mathrm{~kg} / \mathrm{mm}^{2}$, serta raw material dengan harga kekerasan $144.08 \mathrm{~kg} / \mathrm{mm}^{2}$.

\section{Hasil Uji Struktur Mikro}

Hasil pengamatan struktur mikro dari material awal sebelum mengalami pack caburizing dapat dilihat pada Gambar 5 berikut ini:

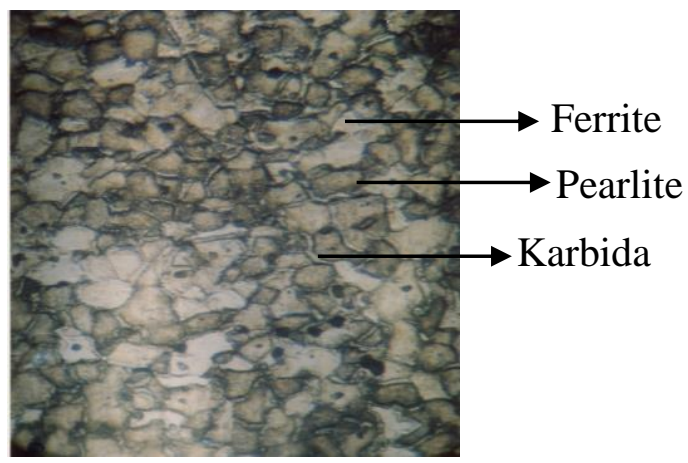

Gambar 5: Struktur Mikro material awal dengan pembesaran $400 \mathrm{kali}$

Dari Gambar 5 menunjukkan bahwa ferrite (berwarna terang dan putih) dan peralite (yang berwarna 
gelap dan hitam) lebih besar ukurannya dibandingkan dengan karbida. Karbida akan membesar jika terjadi perlakuan panas terhadap benda kerja (baja karbon rendah). Kemudian struktur ferrite lebih dominan dari pada struktur pearlite yang lebih sedikit jumlahnya, sehingga kekerasan dari material awal menjadi lebih rendah. Hal ini terjadi karena tidak adanya penambahan unsur karbon yang diberikan pada matrial awal dan sesuai dengan kandungan karbon yang terkandung pada material awal sebesar $0.159 \% \mathrm{C}$.

Hasil pengamatan struktur mikro dari material yang telah mengalami pack caburizing dengan perbandingan konsentrasi $85 \%$ arang kayu jati dan $15 \%$ serbuk cangkang keong emas pada suhu $950^{\circ} \mathrm{C}$ dengan waktu carburizing 6 jam menggunakan media pendingin air tawar dapat dilihat pada Gambar 6 berikut ini.

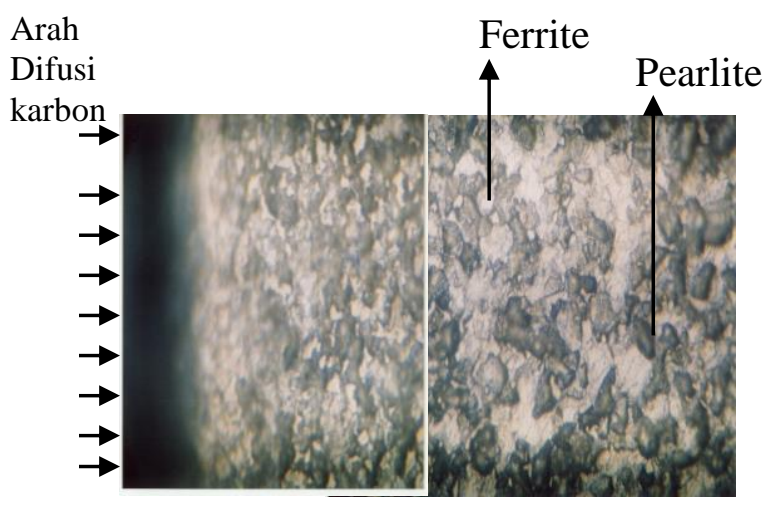

Gambar 6: Struktur mikro dengan pembesaran 400 kali.

\section{Dari Gambar 6 menunjukkan bahwa struktur-struktur perlit jumlahnya semakin banyak dan ukuran butirannya mulai merata di sepanjang penetrasi walaupun pada sisi perlitnya masih terdapat banyak ferit. Peningkatan jumlah pearlite yang lebih banyak dibandingkan dengan struktur mikro material awal dapat terjadi karena adanya pengaruh penambahan unsur karbon ke dalam material selama proses}

difusi intertisi karbon dengan cara pemanasan pada material pada temperatur $950^{\circ} \mathrm{C}$ dengan lama waktu penahan 6 jam serta adanya penambahan serbuk cangkang keong emas dengan konsentrasi $15 \%$ (\%berat) sebagai energizer yang merupakan unsur untuk mempercepat proses difusi karbon ke dalam baja sehingga dapat membentuk struktur pearlit lebih banyak. Sehingga menjadikan spesimen ini menjadi lebih keras dari sebelumnya dan juga di pengaruhi oleh terjadinya proses pendinginan yang cepat sehingga dapat merubah sifat fisis dari pada baja.

Hasil pengamatan struktur mikro dari material yang telah mengalami pack caburizing dengan perbandingan konsentrasi $90 \%$ arang kayu jati dan $10 \%$ serbuk cangkang keong emas pada suhu $950^{\circ} \mathrm{C}$ dengan waktu carburizing 4 jam menggunakan media pendingin larutan garam dapat dilihat pada Gambar 7 berikut ini.

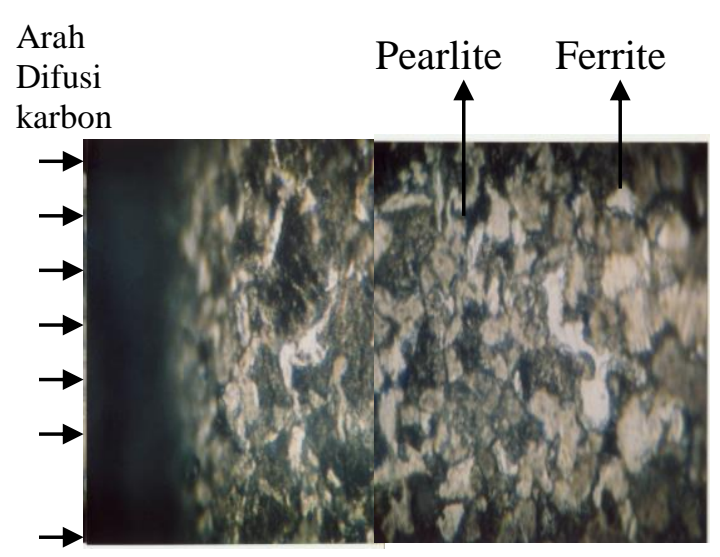

Gambar 7: Struktur mikro dengan pembesaran 400 kali.

Dari Gambar 7 menunjukkan bahwa peningkatan jumah perlit yang paling banyak dibandingkan dengan struktur mikro yang lain, selai itu penetrasi dari karbon juga cukup dalam dan butiranbutiran pada perlit ukurannya lebih besar dibandingkan dengan konsentrasi sebelumnya. Dengan ukuran butir yang lebih besar maka kekerasan yang 
dihasilkan juga akan lebih besar. Ini terjadi karena adanya perbandingan bahan tambahan yang berupa $90 \%$ arang kayu jati dan $10 \%$ serbuk cangkang keong emas sebagai energizer yang merupakan bahan pembangkit tenaga dalam proses karburisasi, serta didukung dengan proses quenching menggunakan media pendingin larutan garam. Hal ini dapat meningkatkan jumlah karbon yang cukup banyak, sehinga pada saat pemanasan berlangsung difusi karbon ke dalam baja menjadi lebih cepat sehingga dapat merubah butir struktur mikro dan nilai kekerasan yang lebih keras di bandingkan dengan material uji sebelumnya .

\section{Hasil Uji Komposisi}

Tabel 2: Hasil Uji komposisi kimia sebelum perlakuan (Raw Material) dan sesudah perlakuan (carburizing) dengan variasi $15 \%$ serbuk cangkang keong emas dengan waktu penahanan 6 jam dan suhu pemanasan $950^{\circ} \mathrm{C}$.

\begin{tabular}{|c|c|c|c|}
\hline No & $\begin{array}{c}\text { Nama } \\
\text { Unsur }\end{array}$ & $\begin{array}{c}\text { Sebelum } \\
\text { Perlakuan } \\
\text { (Raw } \\
\text { material) } \\
\text { Rata-rata } \\
(\%)\end{array}$ & $\begin{array}{c}\text { Sesudah } \\
\text { perlakuan } \\
\text { (carburizing) } \\
\text { Dengan variasi } \\
\text { 15\% serbuk } \\
\text { cangkang dan } \\
\text { waktu tahan 6 } \\
\text { jam } \\
\text { Rata-rata } \\
(\%)\end{array}$ \\
\hline 1 & $\mathrm{Fe}$ & 98.11 & 92.91 \\
\hline 2 & $\mathrm{C}$ & 0.159 & 0.78 \\
\hline 3 & $\mathrm{Mn}$ & 0.624 & 0.70 \\
\hline 4 & $\mathrm{Cr}$ & 0.110 & 1.29 \\
\hline 5 & $\mathrm{Mo}$ & 0.078 & 0.47 \\
\hline 6 & $\mathrm{Cu}$ & 0.241 & 0.34 \\
\hline 7 & $\mathrm{Nb}$ & 0.016 & 0.03 \\
\hline 8 & $\mathrm{Ti}$ & 0.008 & 0.80 \\
\hline
\end{tabular}

Dari data pada Tabel 2 di atas, hasil uji komposisi pada spesimen sebelum dan setelah perlakuan, terjadi adanya peningkatan kadar karbon dimana spesimen sebelum perlakuan (raw materials) mengandung $0.159 \% \mathrm{C}$ sedangkan setelah perlakuan (carburizing) pada bagian permukaan menurut uji komposisi mengandung $0.78 \%$ C. Hal ini membuktikan bahwa karbon telah masuk ke bagian permukaan baja karbon rendah.

\section{KESIMPULAN}

Dari hasil pengujian dan pembahasan dapat disimpulkan bahwa:

1. Dengan penambahan serbuk cangkang keong emas 5\%, 10\% dan $15 \%$ dan waktu penahanan selama 2, 4 dan 6 jam maka nilai kekerasan pemukaan menjadi semakain besar. Nilai kekerasan rata-rata untuk 5\% serbuk cangkang dan waktu penahanan 2, 4 dan 6 jam berturutturut adalah 180.71, 207.21 dan $235.04 \quad\left(\mathrm{~kg} / \mathrm{mm}^{2}\right), \quad 10 \%$ serbuk cangkang dan waktu penahanan 2, 4 dan 6 jam berturut-turut sebesar $190.77, \quad 230.41$ dan 254.33 $\left(\mathrm{kg} / \mathrm{mm}^{2}\right)$ dan sebuk cangkang $15 \%$ dan dan waktu penahanan 2, 4 dan 6 jam berturut-turut sebesar 254.33, 248.18 dan $262.26\left(\mathrm{~kg} / \mathrm{mm}^{2}\right)$.

2. Dari pengamatan foto struktur mikro pada material awal terdapat struktur ferrite yang lebih banyak di bandingkan dengan foto struktur mikro setelah perlakuan (carburizing). Sebaliknya jumlah pearlite setelah perlakuan (carburizing) menjadi lebih banyak dibanding material sebelumnya.

\section{DAFTAR PUSTAKA}

Amanto, H. \& Daryanto, 1999, Ilmu Bahan, Bumi Aksara, Jakarta Arifin, 1977, Ilmu Logam, Ghalia Indonesia, Jakarta

Fatai O. A., Simeon A. I., Isiaka., Oluwole O., and Joseph O. B., 2010, 
"Pack Carburization of Mild Steel, using Pulverized Bone as Carburizer: Optimizing Process Parameters", Leonardo Electronic Journal of Practices and Technologies, ISSN 1583-1078, issue 16, p. 1-12

Jekti, 1990, Diktat Biologi 1, Unram, Fakultas Peternakan, Mataram.

Koswara, Engkos. 1999. Pengujian Bahan Logam. Bandung : Humaniora Utama Press

Setiyawan, A., 2003, Tugas Akhir : Penelitian Mengenai Pengaruh Proses Carburizing Terhadap Sifat Fisis dan Mekanis Sudu Blower Dinamo Ampere pada Mobil Diesel, Universitas Muhammadiyah Surakarta

Suherman, W. 1987, Pengetahuan Bahan, FTI - ITS, Surabaya.

Surdia,Tata, dan Saito, S. 2000, Pengetahuan Bahan Teknik cetakan kelima 